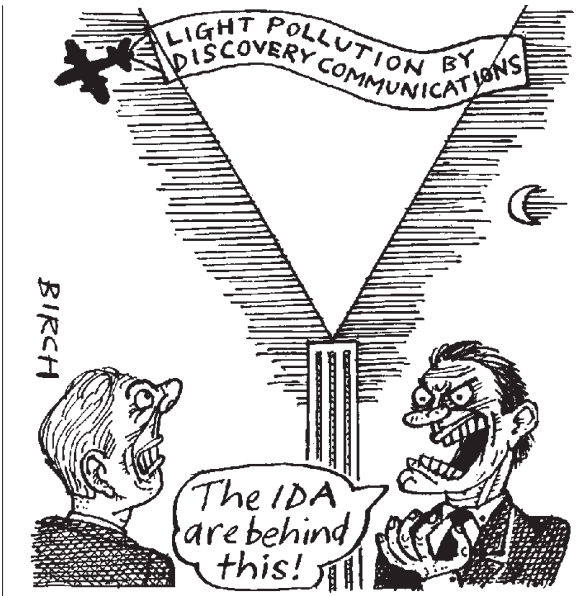

Astronomy Club, an amateur group in Greenbelt, Maryland, which is near Silver Spring. "This is probably the second most polluted area [in the United States] after New York City, and this light will only degrade the quality of life for everyone around here. Its only purpose seems to be an ostentatious display of corporate power," he says.

Settle says that in the Greenbelt area, which is also home to an astronomy club composed of employees at NASA's

Goddard Space Flight Center, star-gazers can see only second-magnitude stars. Spotting fifth- or sixth-magnitude stars, he says, needs more than an hour's drive.

There is no major astronomical research left in the Washington area, and the US Naval Observatory moved its heavy equipment and operations to Arizona more than $\mathbf{4 0}$ years ago.

Geoff Chester, the observatory's spokesman, questions the reason for the planned tower light: "Why would anyone want to waste photons for something that's just going to light up the bellies of airplanes?" However, he doubts whether it will have much impact on the observatory's small-scale work.

But Gent says he has heard numerous complaints, not only from amateur astronomy clubs. "The American Astronomical Society has contacted me. So has the University of Maryland astronomy department," he says.

David Leavy, spokesman for Discovery Communications, says he is unaware of any complaints except for one letter from the IDA. But he admits that a recent article in a local paper about the plans for the building has made the company sensitive to the concerns.

So far, he says, no changes have been made to the design. "But as we go forward we'll be consulting with the organizations to make sure this structure is something... that will be environmentally sound and will not cause any celestial inconvenience." Rest assured, says Gent, the IDA will be watching.

\title{
Educated US public get more wary of genetic engineering
}

Paul Smaglik, Washington

Well-educated Americans have become less keen on genetic engineering over the past five years, according to a survey carried out by the National Science Board (NSB). This is despite a general increase in acceptance of the topic in the previous decade.

The proportion of US adults with bachelor degrees who responded that the potentially harmful results of genetic engineering either 'slightly' or 'significantly' outweighed the benefits is rising, from $20 \%$ in 1995 and $24 \%$ in 1997 to $29 \%$ in 1999.

The results, published last week in the NSB's Science and Education Indicators 2000, point to a growing suspicion of the biotech industry by some sectors of the public, at a time when the industry, prompted by the full sequencing of the human genome (see page 983), is set for greater financial prosperity.

Negative perception of genetic engineering across all US adults has remained sightly less volatile. Adults with less than a college education are still more suspicious of genetic engineering as a whole, while adults who have completed high school or college or who follow progress in medical research have become more suspicious of it since 1995.

But some are sceptical. Dan Eramian, spokesperson for the Biotechnology Industry Organization (BIO), says it "runs counter to every national survey I've seen".
Eramian says the public has little idea of what 'genetic engineering' means. The term encompasses cloning, gene therapy and genetically modified (GM) foods, among other transgenic technologies. Those polled may have responded differently if they had been asked about each specific technology, according to the report.

But Jeremy Rifkin, president of the Foundation on Economic Trends in Washington, a group that opposes GM foods, says that the more BIO promotes the applications of genetics to promote its image, the more people appear to become opposed to it.

Rifkin thinks that the falling support of genetic engineering by educated and informed people reflects uncertainty, rather than panic. "People are saying we don't have enough information to show that this is safe," he says.

Dorothy Nelkin, a professor of sociology at New York University who specializes in science and law, says she is not surprised at the results. People in grass-roots organizations who oppose GM food, she says, tend to be both highly educated and informed of progress in science and medicine.

Nelkin suspects that the public fears industry taking over science more than it fears the science itself. "Commercialization enhances mistrust," Nelkin says.

| http://www.nsf.gov/sbe/srs/seind00/start.htm

\begin{tabular}{|c|c|c|c|c|c|}
\hline \multicolumn{6}{|c|}{$\begin{array}{l}\text { Respondents who argue that the harmful results of genetic engineering 'slightly' or 'strongly' } \\
\text { outweigh benefits }\end{array}$} \\
\hline & 1985 & 1990 & 1995 & 1997 & 1999 \\
\hline All adults & 39 & 37 & 35 & 36 & 38 \\
\hline Male & 35 & 34 & 32 & 21 & 33 \\
\hline Female & 42 & 41 & 38 & 40 & 42 \\
\hline Less than high-school graduate & 36 & 32 & 42 & 44 & 36 \\
\hline Baccalaureate and higher & 31 & 28 & 20 & 27 & 26 \\
\hline "Attentive' to medical research & 36 & 30 & 27 & 30 & 36 \\
\hline
\end{tabular}

\section{Call for more accelerator research}

Quirin Schiermeier, Munich

Luciano Maiani, director-general of the Geneva-based European Laboratory for Particle Physics (CERN), last week called on the organization's 20 member states to put in place a "vigorous programme of accelerator research and development" to help maintain CERN's leading position in particle physics in the long term.

CERN's current core activity, the search for the still elusive Higgs particles, will continue, Maiani told the CERN Council last week. Higgs particles, if they exist, are predicted to be in the range of CERN's new Large Hadron Collider (LHC), experimental work on which is to start next year.

But funding for future work, including the Compact Linear Collider (CLIC) and research into high-intensity proton accelerators aimed at producing a secondgeneration neutrino beam, is "barely sufficient", he said. These projects currently receive around $1 \%$ of CERN's resources. This was acceptable during the construction phase of the LHC, Maiani said, but now "it is time to start a gradual increase". 